\title{
EFFECTIVENESS OF PARENTAL PRESENCE/ABSENCE TECHNIQUE AS A BEHAVIOR MANAGEMENT TECHNIQUE IN PAEDIATRIC DENTSTRY
}

\author{
Fatimah Shiraz, Laila Mustafa*, Nabhan Zakir**, Madeeha Bangash, Gulandama Alam Khan, Ammara Sami \\ Rehman College of Dentistry, Peshawar Pakistan, *Shifa International Hospital, Islamabad Pakistan, **SHO General Medicine, Pakistan,
}

\begin{abstract}
Objective: To assess the deliberate use of a parental presence/absence (PPA) intervention as a behavior management technique to manage uncooperative children as well as its association with age.

Study Design: Cross sectional study.

Place and Duration of Study: Study was conducted at department of Paediatric dentistry, Rehman College of Dentistry, Peshawar, from Jan to Apr 2019.

Methodology: Practice patient records were examined over a period of 3 months, during which Frankel behavior ratings were made for each patient. About 2 to 14 years olds were included in the study who had no previous dental treatment, accompanying by their parents. Sixty one children were selected out of 200 who showed uncooperative behavior Frankl 1 and Frankel 2. Their parents were asked to step out of the operatory until the patient become cooperative.

Result: The study included 61 children out of 200 who showed uncooperative behavior according to Frankel's behavior rating scale. The result showed significance in age group 4-6year, kinder garden $(p=0.035)$.

Conclusion: The Parental Presence/Absence technique (PPA) can be successfully used in gaining the cooperation of children displaying negative behavior aged 4-6, thus minimizing the need for other more aversive Behavior management techniques (BMT's).
\end{abstract}

Keywords: Behavior management, Parental presence, Parental absence, Pediatric dentistry.

This is an Open Access article distributed under the terms of the Creative Commons Attribution License (http://creativecommons.org/licenses/by/4.0), which permits unrestricted use, distribution, and reproduction in any medium, provided the original work is properly cited.

\section{INTRODUCTION}

Children visiting dental office exhibit a marked fear and anxiety about their dental procedure which often culminatesin a wide variety of negative attitudes and behaviors There fore, a plethora of behavior management techniques are employed for children during theirdental treatment to lessen their fear and anxiety so that the dental practitioners can inspire a positive patient dental attitude, deliver good-quality dental care, establish communication and build a trustworthy relationship between the child and the dental team Wright" ${ }^{1}$, suggested that a "positive dental atti-tude" was the aim of behavior management. In 1895, McElroy wrote: "Although the operative dentistry may be perfect, the appointment is the failure if the child departs in tears ${ }^{2}$.

Behavior management techniques (BMT's)

Correspondence: Dr Madeeha Bangash, HOD of Paediatric Dentistry, Rehman College of Dentistry, Peshawar Pakistan

Received: 29 Jul 2020; revised received: 01 Oct 2020; accepted: 05 Oct 2020 are considered pertinent in pediatric dentistry. In the absence of such set of skills, dentists would not be able to deliver appropriate and safe treatment. There are several non-pharmacological BMTs such as tell-show-do, positive reinforcement, distraction, voice control, nonverbal communication, and parental presence/absence. While the techniques are used separately, they can also be used in combination. The application of the BMTs relies heavily on patients' needs and conditions as well as the dentist preference and skills and the approval of parents 2 .

Parental presence/absence (PPA) is common type of the nonpharmacological BMTs. In this technique, the parental presence is used as a factor to manage the child's negative behavior to dental management ${ }^{2}$. Whether a parent should be present or not during a dental appointment is a dilemma among pediatric dentists because complete parental separation might cause emotional trauma to the child 6 . In addition to that, some parents would not agree on their children being 
out of sight, which will be ahindrance to the dental.

Literature on dental and psychological aspect differed in opinions on this technique. Olsen $^{3}$, stated that a child should not be isolated from the parent at the first appointment as it helps in the psychological analysis of the future child behavior. Frank et al ${ }^{4}$. 2 investigations showed that children of age 3-4 years were more cooperative when mother was presentin the operatory. The author concluded that proper instructions given to the mother can help in establishing a good rapport between the child and the dentist. Lewis and Law ${ }^{5}$, found no difference between the mother-presence and mother-absent groups. The rational of the study was to access effectiveness of PPA technique as effective BMT as well as its association with age.

This article explains the deliberate use of PPA technique to improve child cooperation in one dental visit. The aim of this study was to assess the relative success of PPA techniqueand its association with age as a BMT in the pediatric dentistry and to gain child's cooperation without causing traumatic impact as a result of complete parental separation.

\section{METHODOLOGY}

This cross sectional study was conducted in the Department of pediatric dentistry, Rehman College of Dentistry, Peshawar, Pakistan over a period of 3 months (January 2019- April 2019). Informed consent was taken from all the patients and ethical approval was taken from ethics review board (IERB) of Rehman College of dentistry (EC Ref. No: RCD-20-03-007) prior to data collection. All trained paedodontists provided the dental treatment with trained dental auxiliaries from the pediatric department. The subjects for this study were 61 children selected from a sample of 200 children by non-probability sampling technique (using WHO calculator), who showed uncooperative behavior over the period of 3 months. The inclusion criteria for the study was; No previous dental experience (first visit) ages of
2 to 14 years, Mentally and physically healthy, Children accompanying parents.

Treatment provided ranged from simple scaling to restorative pulp therapy and extraction. The data variablesincluded age, gender,presence of parents, and assessment of patient's behavior before and after the application of PPA technique.

We divided the children into 4 groups. Group 1 preschool children (age 2 to 3), group 2 kinder-garden (age 4-6), group 3 primary school (age 7 to 9), and group 4 middle school (age 10 to 14). Behavior rating of children were obtained using Frankl's behavior rating scale 4-point. Index to obtain cooperation level described in (table-I). These ratings were made for every aspect of a child's dental treatment. All healthy children demonstrating cooperative behavior (Frankl 3 and Frankl 4) according to Frankl behavior rating scale were excluded from this study.

\begin{tabular}{c|l} 
Table-I: Franklbehavior rating scale. \\
\hline Rating & Description \\
\hline 1 & $\begin{array}{l}\text { Definitively Negative: Refusal of } \\
\text { treatment, crying forcefully, fearful, or } \\
\text { any other overt evidence of extreme } \\
\text { negativism }\end{array}$ \\
\hline 2 & $\begin{array}{l}\text { Negative: reluctant to accept treatment, } \\
\text { uncooperative, some evidence of negative } \\
\text { attitude but not pronounced, sullen, } \\
\text { withdrawn }\end{array}$ \\
\hline 3 & $\begin{array}{l}\text { Positive: Acceptance of treatment, at } \\
\text { times cautious, willingness to comply } \\
\text { with the dentist, at times with reservation } \\
\text { but patient follows the dentist's } \\
\text { directions cooperatively }\end{array}$ \\
\hline 4 & $\begin{array}{l}\text { Definitively positive: Good rapport } \\
\text { with the dentist, interested in the dental } \\
\text { procedures, laughing and enjoying the } \\
\text { situation }\end{array}$ \\
\hline
\end{tabular}

No invasive techniques were used in this practice during the time of the study. An oral and written consent was taken from the parents before the procedure began so that if a child demonstrates a negative behavior then the parent will be asked to leave the operatory room. This agreement between the dentist and parent was made before the child was seated in the dental chair, as 
it was important that the child knows about the agreement. At the beginning of the procedure, the parent remained in the operatory room as a silent observer or was seated near the child without disrupting the interaction between the dentist and the child ${ }^{2}$. If the child continued to be uncooperative, the parent was asked to leave the department.and stand behind a wall or transparent barrier (mirror wall). The child was informed in a veryempathic way, that his/her parent will return the operatory room until they do not show cooperative behavior. During the time-period when the parent is outside the dentist tries to establish good communication with the child, by talking in short and soft phrases with the child. At this point when the child shows cooperative behavior then the parent is called back in. And if the child behavior does not improve after 8 minutes, then the appointed was terminated. Data were computed using SPSS version 25. The observed significance level ( $p$-value) test was computed. Descriptive statistics were performed for frequencies, percentages. In order to analyze correlation between the PPA technique and different age groups, Pearson's correlation was done. $p$-value of $<0.05$ was considered significant. Sample size was calculated using WHO calculator.

\section{RESULT}

In our study the sample size was 200. During the study period 61 children presented as Frankl "negative" ( $\mathrm{n}=24)$ and 'definitively negative' $(n=37)$. Figure- 1 shows that females were slightly more uncooperative in comparison to the males. However, the correlation between the.gender and child behavior was not significant. This difference can be a result of biological origin or reflect a response bias as a fearfulness is more socially accepted in girls and may be a result of culture and social beliefs.

Results according to Frankl rating scale showed in table-II that in group 1 (preschool children age 2-3 years) all 7 children visited for dental treatmentat first visit showed uncooperative behavior. Among these none showed positive behavior after the application of PPA technique $(p=$
NC) as shown in table-III. Result shows that PPA is remarkedly insignificant in this age group as the child does not understand the technique and does not accept to leave the parent as they are mostly in mother's lap.

As the age increases the number of patient's surge in the pediatric dentistry. According to the resultin group 2 (kidder garden age 4-6 years) as shown in table-II, total of 27 children were un-

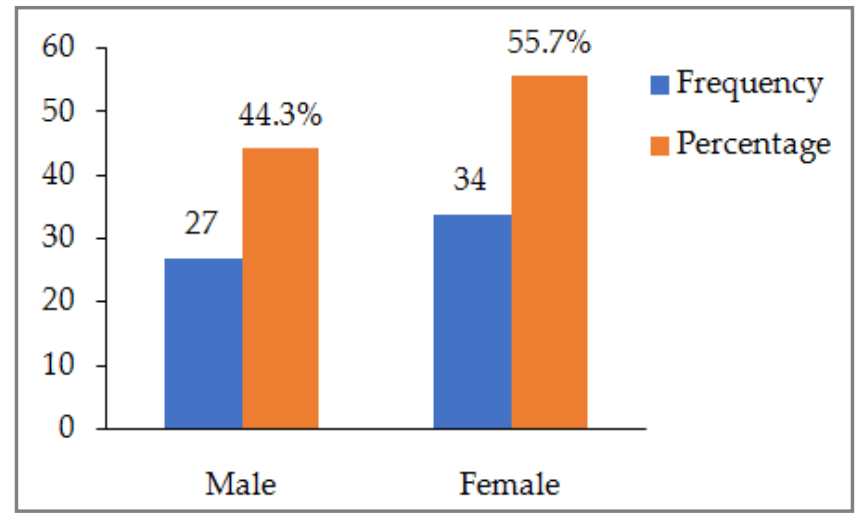

Figure-1: Comparison between both genders for level of co-operation.

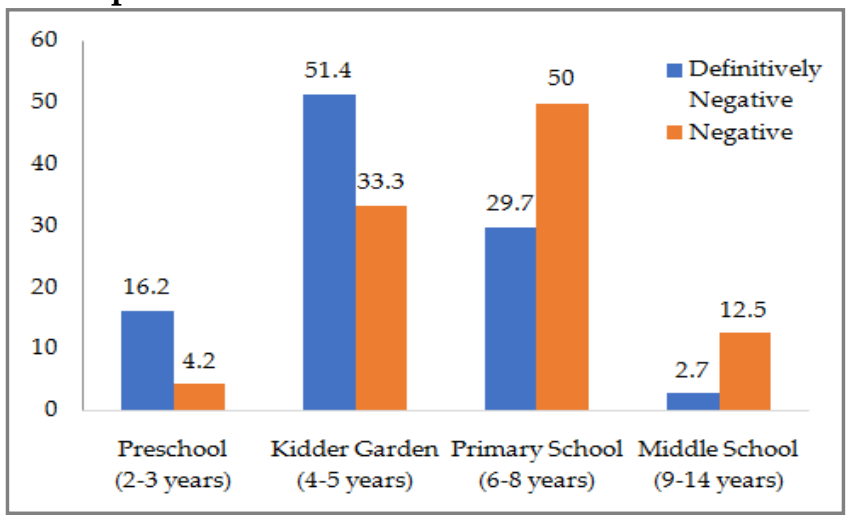

Figure-II: Association of parental presence/absence (PPA) technique with different age groups.

cooperative. According to the results more uncooperative behavior was in seen in this group. A significance correlation was found in 4-6 years old children and improvement of PPA $(p=0.035)$, shown in table-III. Frankl et al9, found that 4149 months old were more cooperative in the presence of mother.

As the age of the child inclines the ability to understand the technique grows. Therefore, more children get cooperative as the age, with the app- 
lication of the PPA technique. In group 3 (primary school age 7-9 years) total 23 children were uncooperative (table-II). Among these 8 children showed positive behavior $(p=0.1190)$ which was not significant (table-III).

Age group above 10 years, group 4 (middle school age 10-14 years) shows a uniform positive behavior and willingness to cooperate and undergo necessary treatment (table-II). Only 4 children in our study revealed negative behavior and were followed by PPA and showed positive behavior $(p=\mathrm{NC})$ shown in table-III.

Table-II: Behavior management relative to age of children.

\begin{tabular}{l|c|c}
\hline Age group & $\begin{array}{c}\text { Definitively } \\
\text { Negative }\end{array}$ & Negative \\
\hline $\begin{array}{l}\text { Preschool children } \\
\text { (2-3 years) }\end{array}$ & $6(16.2 \%)$ & $1(4.2 \%)$ \\
\hline $\begin{array}{l}\text { Kidder garden } \\
\text { (4-6 years) }\end{array}$ & $19(51.4 \%)$ & $8(33.3 \%)$ \\
\hline $\begin{array}{l}\text { Primary school } \\
\text { (7-9 years) }\end{array}$ & $11(29.7 \%)$ & $12(50.0 \%)$ \\
\hline $\begin{array}{l}\text { Middle school } \\
\text { (10-14 years) }\end{array}$ & $1(2.7 \%)$ & $3(2.7 \%)$ \\
\hline Total & 37 & 24 \\
\hline
\end{tabular}

Table-III: Behavior improvement after the application of parental presence/absence (PPA) technique.

\begin{tabular}{l|c|c|c}
\hline Age Group & Improved & $\begin{array}{c}\text { Not } \\
\text { Improved }\end{array}$ & $p$-value \\
\hline $\begin{array}{l}\text { Preschool } \\
\text { children } \\
\text { (2-3 years) }\end{array}$ & - & $7(100 \%)$ & $\begin{array}{c}\text { Not } \\
\text { changed }\end{array}$ \\
\hline $\begin{array}{l}\text { Kidder garden } \\
\text { (4-6 years) }\end{array}$ & $4(14.8 \%)$ & $23(85.1 \%)$ & $0.035^{*}$ \\
\hline $\begin{array}{l}\text { Primary } \\
\text { school } \\
\text { (7-9 years) }\end{array}$ & $8(34.7 \%)$ & $15(65.2 \%)$ & 0.1190 \\
\hline $\begin{array}{l}\text { Middle school } \\
(10-14 \text { years) }\end{array}$ & $4(100 \%)$ & - & $\begin{array}{c}\text { Not } \\
\text { changed }\end{array}$ \\
\hline Total & $16(26.2 \%)$ & $45(73.7 \%)$ & \\
\hline$p \leq 0.05$ was considered significant. & &
\end{tabular}

Children in the age-group 7-14 years old are significantly cooperative compared to the 2-8 years old children as shown in table-II. And that parental presence made no difference. This again means the ability to comply with dental treatments grow with age. Implementation of the PPA technique on different age group shows significance in only 4-6 years old children whereas other groups shows no significance (table-III).

\section{DISCUSSION}

Fear isanatural response whenencountering new situations, and fearful situations might end up in behavior management problems in children. However, these twophenomena have an overlap with each other, as in this study 61 of fearful children also have behavior management problems.

Dental fright and behavior are likely to have multifactorial origins apart from developmental age 6-8, can be broadly divided into personal characteristics, environmental factors, or situational factors 9 . Personality characteristics can have some impact on behavior. In addition, social and family environments can also affect as Klingberg et al ${ }^{10}$. Documented that dental fear might not be always present in all children having behavior management problems.

Among environmental factors, it is reported that child dental anxiety is greatly influenced by parents panicin the dental surgery ${ }^{11}$. So, one of the reasons for the child to be uncooperative is parental anxiety which is being transferred to the child which further prevents dentist-patient communication and delivery of care ${ }^{1}$. Child behavior could be influenced negatively by an anxious parent ${ }^{10}$. In such cases parental presence/absence (PPA) technique is used in which the parent is not allowed to interfere with the dentist and child communication.

Environmental and situations factors such as socioeconomic status, family situation, frequent exposure to invasive medical care, and past experience of operative dental care have been explored as potential causes of dental fear and behavior problems, but theresults have been inconsistent ${ }^{12-15}$.

Significance of the effect of gender on child behavior was also assessed. In our study there was no significant difference found in behavior related to gender. As mentioned by Wright and 
Alpern ${ }^{16}$, Frankl et al ${ }^{9}$, and Venham ${ }^{17}$. However, a slightly higher count of female children (55.7\%) showed uncooperative behavior than male children $(44.3 \%)$. This finding agrees with most of the studies ${ }^{18-20}$, but somewhat different from that of Shirley and Poyntz ${ }^{21}$, who found boys consistently more upset than girls. Furthermore, higher muscular tension occurs in children because of the posture of the dental chair resulting in increased sensitivity to dental stimuli and increased anxiety. In female patients the stimuli rendering them more anxious are usually the noise of the dental drill as well as the sight of dentists handling needles and our results are consistent with these findings 22 .

According to this study, to manage child's negative behavior the presence or absence of the parent sometimes can be used togain the patient's attention and improve behaviors, establish appropriate dentist-child roles, and enhance effective communication among the dentist, child, and parent, also to minimize anxiety and achieve a positive dental experience; and facilitate rapid informed consent for changes in treatment or behavior guidance. In this study PPA technique was able to result cooperation in age group 4-6 years old without the use of psychopharmacological agents. Age group of 2-3 years old did not respond to the technique as they were usually in mothers lap and were unable to understand the technique and communicate. Parents will always want to stay with their kids during dental treatment as well as during examination andasking parents to leave the operatory makes the patient more panicky.

In our study, age was significantly related with the child's behavior. This shows that child behavior in dental operatory is greatly influenced by his age as reported by several studies as Klingberg et al23, Brill24. As in this study children 2-3 years old were highly uncooperative, and the cooperation level climbed with increasing age. The ability to comply with dental treatments inclines as the ability to understand and communicate increments with age. Thus, all grown up children responded more to PPA technique. In others age groups the technique appears promising, it is not known whether it is the technique itself, or other non-specific factors such as the manner in which the technique has been delivered by the dentist, which contributes to its success.

\section{CONCLUSSION}

Parental presence in the dental surgery is recommended to gain child support emotionally. It is used to avoid the stress related to parent's separation especially in early ages and in patients with special health care needs. In case of noncooperative child, PPA technique can be used as a behavior management technique to help dental gain the child's cooperation without traumatizing him/her emotionally. PPA technique can be used with or without other BMTs.

\section{CONFLICT OF INTEREST}

This study has no conflict of interest to be declared by any author.

\section{REFERENCES}

1. Wright GZ, Lenchner V. Practical considerations for behavior management in Behavior Management in Dentistry for Children WB Saunders Co. Philad Lond Toron 1975 [Internet]. https:// drmirkarimi.ir/wp-ontent/uploads/2017/07/Behavior-

Management-in-Dentistry-for-Children.pdf

2. Riba H, Al-Shahrani A, Al-Ghutaimel H, Al-Otaibi A, AlKahtani S. Parental Presence/Absence in the Dental Operatory as a Behavior Management Technique: A Review and Modified View. J Contemp Dental Prac 2018; 19(2): 237-43.

3. Olsen NH. The first appointment--a mutual evaluation session. J Dent Child 1965; 32(4): 208-11.

4. Frankl SN. Should the parent remain with the child in the dental operatory?. J Dent Child 1962; 29(1): 150-63.

5. Lewis TM, Law DB. Investigation of certain autonomic responses of children to a specific dental stress. J Am Dental Associa 1958; 57(6): 769-77.

6. Phillips JL. The origins of intellect: Piaget's theory. Macmillan; 1975 [Internet]. https://www.amazon.com/Origins-IntellectPiagets-Theory/dp/0716705796.

7. Piaget J. Judgment and Reasoning in the Child Totowa. NJ: Littlefield Adams. 1964 [Internet]. https://www.biblio.com/ judgment-and-reasoning-in-by-piaget-jean/work/355661.

8. Wright GZ, Starkey PE, Gardner DE. Managing children's behavior in the dental office. Mosby 1983 [Internet]. https://www. amazon.com/Managing-childrens-behavior-dental-office/dp/ 0801656664

9. Suprabha BS, Rao A, Choudhary S, Shenoy R. Child dental fear and behavior: the role of environmental factors in a hospital cohort .J Indian Soc Pedod Prev Dent 2011; 29(2): 95-01.

10. Klingberg G, Berggren U, Carlsson SG, Noren JG. Child dental fear: cause related factors and clinical effects. Eur J Oral Sci 1995; 103(6): 405-12.

11. Arnrup K, Berggren U, Broberg AG, Lundin SA, Hakeberg M. Attitudes to dental care among parents of uncooperative vs. 
cooperative child dental patients. Europ J Oral Sci 2002; 110(2): 75-82.

12. Colares V, Richman L. Factors associated with uncooperative behavior by Brazilian preschool children in the dental office. J Dent Child 2002; 69(1): 87-91.

13. Gustafsson A, Arnrup K, Broberg AG, Bodin L, Berggren U. Psychosocial concomitants to dental fear and behaviour management problems. Int J Paediatr Dent 2007; 17(6): 449-59.

14. Klingberg G, Berggren U, Carlsson SG, Noren JG. Child dental fear: cause-related factors and clinical effects. Eur J Oral Sci 1995; 103(6): 405-12.

15. Kyritsi MA, Dimou G, Lygidakis NA. Parental attitudes and perceptions affecting children's dental behaviour in Greek population. A clinical study. Eur Arch Paediatr Dent 2009; 10(1): 29-32.

16. Wright GZ. Variables influencing children's cooperative behavior at the first dental visit. J. Dent Child 1971; 38(2): 124-28.

17. Venham LL. The effect of mother's presence of child's response to dental treatment. ASDC J Dent Child 1979; 46(3): 219.
18. Klingberg G, Broberg AG. Dental fear/anxiety and dental behaviour management problems in children and adolescents: a review of prevalence and concomitant psychological factors. Int J Paediatr Dent 2007; 17(6): 391-06.

19. Folayan MO, Idehen EE, Ojo OO. The modulating effect of culture on the expression of dental anxiety in children: a literature review. Inter J Paediat Dentistry 2004; 14(4): 241-45.

20. Townend E, Dimigen G, Fung D. A clinical study of child dental anxiety. Behav Res Therapy 2000; 38(1): 31-46.

21. Shirley MM, Poyntz L. Children's emotional responses to health examinations. Child Develop 1945; 16(1/2): 89

22. Peretz B, Mann J. Dental anxiety among Israeli dental students: a 4 year longitudinal study. Eur J Dental Educ 2000; 4(3): 133-37.

23. Klingberg G, Berggren U, Noren JG. Dental fear in an urban Swedish child population: prevalence and concomitant factors. Community Dental Health 1994; 11(4): 208-14.

24. Brill W. Child behavior in a private pediatric dental practice associated with types of visits, age and socio-economic factors. J Clin Pediatr Dent 2001; 25(1): 1-7. 